EDITORIALES

\title{
OPUS IUSTITIAE PAX
}

El escudo de Pío XII tenía en la parte superior una paloma llevando la rama de olivo en el pico. Debajo, el pie del símbolo: "Opus iustitiae pax"; la paz, obra de la justicia. Este iba a ser el mote de su pontificado, el ideal de sus casi veinte años de piloto en la barquilla del Pescador.

$$
* * *
$$

Preveía horas difíciles. Su penetración psicológica de los hombres, y su paso por las Nunciaturas, Legaciones, Embajadas solemnes, le permitían adivinar páginas no escritas aún en el libro de los acontecimientos humanos. Cuando da su consentimiento a su elección para el Pontificado, en la tarde del 2 de marzo de 1939, nubes negras hacen presagiar la tormenta que estalla en septiembre del mismo año, a pesar de sus es-

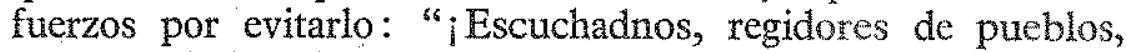
hombres de la política y las armas, escritores, oradores de radio y tribuna; os hablamos en nombre de Dios, sin más armas que la palabra de la Verdad! ¡Inminente es el peligro, pero aún es tiempo!"

Urgente llamada que golpea en la piedra de intereses egoístas. Se entabla la lucha; se llevará a cabo la fatídica primera explosión atómica de la historia, y la guerra hace acto de presencia a su lado, con el bombardeo de Roma, julio 1943, que da ocasión para que sobre el trágico escenario, aparezca la fi- 
gura blanca, como un ángel de paz, que va cicatrizando las heridas con el bálsamo del amor.

$$
* * *
$$

Los seis primeros mensajes navideños, con el saludo paterno y universal, irán marcando rutas de paz hacia Belén. Y cuando, acallado el estruendo bélico, siguen los dos bloques enfrentados mostrando la amenaza de su potencial destructor, Pío XII tiene que expresar con amargura: "Al acercarse la Navidad quisimos ofrecer al Príncipe de la Paz un mundo pacificado formando una sola familia, pero nos fué reservada en los seis primeros años la amargura sin nombre de ver en torno a Nos tan sólo pueblos en armas, arrebatados por el insano furor de la destrucción mutua. $Y$, a la guerra fría, ha sucedido la paz fría, que si no es precisamente estado de guerra, tampoco es de paz; es una calma fría, viviendo en recelo por los efectos de las armas novísimas los dos campos, con la angustia de ver cada uno el desarrollo del otro."

$$
\star \star \star *
$$

El don de la palabra fué uno de los carismas extraordinarios de Pío XII; su instrumento providencial de apostolado. Palabra cálida, al día, sin fórmulas hechas ni tradicionalismos sin compromiso: para la última llaga el último remedio. La mente trabajadora de los hombres buscando evasiones o disculpas para salirse de las imposiciones de la moral con apoyo en descubrimientos nuevos, en la técnica perfeccionada, no le sorprenden; tiene siempre la palabra oportuna, el criterio firme sintonizado con el avance científico. En la mañana del 27 de octubre de 1957 inaugura la nueva emisora de Radio Vaticana, que le pone en comunicación con todo el mundo, ansioso de su palabra de paz, a pesar de la paradoja de no saber vivir los hombres, al parecer, más que para la guerra. Ha agrandado el instrumento que lleva su palabra hasta los últimos confines: "Nadie seguramente habrá que, juntamente con Nos, no alabe 
estos descubrimientos que constituyen una gloria de nuestro siglo."

La pluma y el micrófono han trabajado denodadamente a su servicio; de día y de noche; cuando la noche imponía silencio en la Plaza de San Pedro, la ventanita del tercer piso seguía iluminada como faro orientador.

Veintiocho grandes Encíclicas de Magisterio salieron en momentos clave; los Mensajes, Alocuciones, Discursos, se cuentan por centenares. Solamente a los españoles nos dirigió quince Radiomensajes y cuarenta y cuatro Discursos.

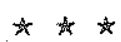

Preocupación y programa para su pontificado: la Paz.

Para nuestros juristas clásicos, la Paz es orden y equilibrio. Es armonía de voluntades. Es - desentrañando la concisión agustiniana- tranquilidad en el orden, basado en la justicia y la caridad. Así es posible la convivencia pacífica para la prosperidad y bienestar de todos.

Para Pio XII, como para nuestros tratadistas, la Paz no es quietismo inoperante, impotente conformismo, resignación callada ante el abuso y la injusticia. El sabrá fundamentar la paz duradera, no la ficticia ni la falsa, en principios eternos con aplicaciones concretas a los casos de cada día.

Ante su vista se despliega el mundo; ve fallos profundos en el orden internacional; y los señalará con valentía, porque es el médico que ausculta paciente y comprensivo, pero sincero, para poner el remedio que exige el diagnóstico: conculcación del Derecho internacional, abuso de las pequeñas naciones, imposición de la ley del más fuerte, endiosamiento de la fuerza, egoísmo, anemia religiosa.

Así no se logra una paz duradera. El silencio que imponen las armas, se rompe a la vuelta de pocos años con el lenguaje de la venganza: los tratados basados en la imposición de la fuerza, ni tienen validez por su acción, ni son otra cosa que papel mojado totalmente irrisorio. El año 1901 se firmaron contratos, se sellaron compromisos; y el 1914 quedaron trágica- 
mente anulados con el estallido del conflicto europeo que costó más de diez millones de muertos a Francia y Alemania. Desgraciadamente se iba a superar el record en 1939 al 45 , con la cifra de catorce millones de muertos para ambas naciones.

In esa agitación inseguridad, hay algo que flota sin hundirse: el anhelo de un mundo nuevo social mejor. Idea que domina en la Conferencia Europea de Trabajo de Salzbrunn y en la Conferencia Internacional del Trabajo de las Naciones Unidas, de Filadelfia, en el "Plan Beveridge" y en el "Plan Wallace"; en la Carta del Atlántico, reunión de Yalta, etc. Los hombres de las naciones grandes que coinciden en la trayectoria de Pio XII, van bajando al sepulcro sin el acierto del Pontífice en señalar programas eficaces para la paz. Por eso, ante el tribunal de la Historia y ante el "pueblo", habrá aprecio más sincero para él que para Stalin, Hitler, Mussolini, Roosevelt...

Pío XII fijará ante los estadistas y dirigentes de las naciones que la paz únicamente viene sobre la convivencia en el orden y en la tranquilidad; porque únicamente sobre una sociedad así -nacional o internacional- puede esculpirse la sentencia: "La paz es efecto de la Justicia"; sin oposición, ni alternativa -amor o derecho-, sino en síntesis fecunda: amor y derecho. Recuerda los grandes principios básicos: "Victoria sobre el odio que divide a los pueblos; confianza en las relaciones internacionales: los Estados no están por encima de la Moral; victoria sobre el utilitarismo político -la utilidad, base y regla del Derecho-; victoria sobre la excesiva desigualdad en el campo de la economía mundial; respeto a los tratados; limitación de armamentos, facilitando el paso al amor, como la Iglesia de Cristo lo inspira, cooperando con ella al inmenso trabajo de curar las heridas de la guerra.

$$
\star \star \star \star
$$

Ante su tribunal, sin soborno, llegan las acusaciones y recriminaciones del mundo de la empresa, que chocan en sus limpios oídos, como oleaje amargo, en confusión: 'jornales de 
hambre, injusticias, pingües ganancias, balances de escándalo, sabotaje, boicot.

También la paz interna de los pueblos está amenazada. $Y$ hay que afianzarla o ganarla con sacrificios y justicia. Ganar la paz; porque el verdadero anhelo de paz del cristianismo es fuerza, no debilidad; lucha, apoyado en Dios y en el orden por El establecido.

Por desgracia, la lucha por la vida, la preocupación por el trabajo y por el pan, dividen en campos adversos a hombres que habitan en la misma tierra y trabajan en una misma empresa. Ante este panorama se enfrenta gallardamente con el problema de la falta de paz interna. Para Pío XII tho se hizo el pesimismo. Cuando contempla el paso macabro de almas muertas, lanza el programa del Mundo Mejor, que se ha hecho slogan en nuestros días. Cuando parece que las olas del materialismo amenazan con amarguras y bajezas de cieno, su voz domina el desaliento: "No decaiga vuestro valor; hay que reconstruir un nuevo mundo social para Cristo."

El crecimiento constante del proletariado pone en primer término sus justas reivindicaciones. No las soslaya; marca, ante todo, entre los pilares fundamentales para la paz, la dignidad y derechos de la persona humana, la defensa de la familia, la dignidad y prerrogativas del trabajo, aprobando y bendiciendo, como peticiones justas, el salario necesario, la solución de los tiempos de enfermedad, paro, vejez, la formación cultural de los hijos, y la elevación del trabajador hacia puestos importantes en la empresa. En el cincuentenario de la "Rerum Novarum", ante el tenebroso horizonte, marca la obligación seria del buen uso de los bienes materiales, el derecho y deber del trabajo, la propiedad familiar. Y en junio de 1941 afirma sin paliativos que la riqueza no es la abundancia de bienes, sino su buena distribución; hasta tal punto que una mala distribución va contra la economía nacional.

$$
\star \star \star *
$$

En los días de Pío XII se habló mucho de la justicia social; estando gran parte del mundo al margen del derecho, todo se 
ha querido arreglar con imposiciones severas de justicia. Cuanw do la atención ha estado, no precisamente en la sala de los trimbunales, ni la pasión se ha ido tras la cátedra del jurista de fama, sino que el comentario que captaba el interés era el último adelanto de la ciencia, midiendo su potencial destructor, todo el mundo ha tenido la justicia en sus labios.

La caridad; si reinara en el mundo, ella sola sería ley, dice Luis Vives; y lo afirma categóricamente Plo XII, dándole puesto en vanguardia cuando para ella se tenía mirada de conmiseración, de desprecio casi, a lo más de benévola acogida en algunos, como se admite que en lo áspero y duro de las guerras, vaya la cariñosa asistencia de las enfermeras de la Cruz Roja restañando las heridas y componiendo vendajes; algo femenino.

Pío XII, el preocupado por sentar la justicia, será su gran panegirista: "La caridad cristiana una debilidad? Sí, la debilidad de Dios, porque El es la Caridad." El egoísmo del capitalismo ateo condena, por labios de Spengler, "el afeminado amor al prójimo"; rebate el Papa este indigno concepto: "iDesgraciados los insensatos que, ebrios de furor, han jurado matar esta virtud inmortal! ¡Desgraciados los fariseos de alma seca y mirada vacía que no ven el resplandor de su
rostro!"

Amor, que no es la inclinación que se llama amor sensitivo; en él falta el elemento intelectual que en todo amor humano es esencial; y además está sobre cualquier humano vulgar, que podría apellidarse flantropía, humanitarismo..., pero no caridad; no es quitar de en medio los males del prójimo, para que no exciten los nervios, no sirvan de acusadores, porque si no se fundamenta en Dios, terminará por herir y soliviantar a aquellos que se trataba de aliviar.

Caridad que ha de tener, como aspecto interesante, el de caridad-justicia. Comprendiendo la situación de hecho, iluminado el camino para dar con la solución, cicatrizando las heridas abiertas y logrando que las dos se complementen, ya que, en frase feliz de San Bernardino de Sena, "la caridad es la perla de la justicia". "QQué buena y más que nunca necesaria 
para esta humanidad agitada y convulsa, que no quiere creer más en la verdad, que no se aureve a creer más en la justicia, pero que no puede decidirse a dejar de creer en la caridad! infelices los falsos profetas de la felicidad universal, cuyas pupilas ardientes se abrasan contemplando el fantasma tenebroso de una justicia terrena completa y no ven en la caridad sino una intrusa e inoportuna que viene a ultrajar a su hermana!"

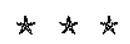

Así habló "el hombre más amado de nuestros tiempos". Los brazos de Pacelli, abiertos en cruz sin límites, que parecian. dejar patente el corazón, quedarán mucho tiempo en imagen viva ante los ojos de millares de peregrinos; cuando, en la última audiencia, se le negaron a levantarse por falta de fuerzas fúsicas, brotó de sus labios un "adiós" débil como un presentimiento de definitiva despedida. Quedaba su programa; y las claras consignas para realizarlo.

Queda su largo e intenso magisterio. Las revistas se han enriquecido frecuentemente con su luz. También la nuestra le ha tenido como guía continuo. Pecaríamos de ingratos no dedicándole un recuerdo póstumo. Y más, persuadidos de que sus enseñanzas tienen toda la actualidad de los días en que las Agencias multiplicaban rápidamente sus Mensajes, porque sabían que el mundo los esperaba con ansia.

\section{OBCEDIENTIA ET PAX}

De momento, apenas otra cosa que dar gracias al Señor por haber puesto al frente de la Iglesia a Juan XXIII.

Recoger la preocupación de su corazón y ofrecerle nuestras personas, cuanto somos y tenemos, la actividad personal y las páginas todas de nuestra Revista "al servicio de la verdad, sin traicionarla nunca", para lograr que sobre el mundo se asiente "una paz con justicia". "Las armas monstruosas" enconan los 